\title{
Attitude, Anxiety, Psychological Effects and Prevention during COVID-19 in India
}

\author{
Debabrata Singh ${ }^{1}$, Shakti Ketan Prusty ${ }^{2, \star}$, Suman Sekhar Sarangi ${ }^{1}$, Surjeet Sahoo ${ }^{3}$, \\ Anil Kumar Biswal'
}

'Department of CSIT, ITER, Siksha 'O' Anusandhan (Deemed to be University), Bhubaneswar, Odisha, INDIA.

${ }^{2}$ School of Pharmaceutical Sciences, Siksha 'O' Anusandhan (Deemed to be University), Bhubaneswar, Odisha, INDIA.

${ }^{3}$ Department of Psychiatry, IMS and SUM Hospital, SOA (Deemed to be University), Bhubaneswar, Odisha, INDIA.

\begin{abstract}
With previous health warnings, personal anxieties could feed behavioral changes with many people of India considering notable changes in their transportation use and anticipating in preparation the purchase of goods, particularly masks. Asian respondents were especially likely to have talked about the pandemic with friends, whereas onefourth of respondents globally had talked about the pandemic with their family. Our data on the correlation indicates that these conversations may increase existing rates of anxiety. Practitioners need to be mindful that rumors spread rapidly during periods of pandemic danger, with significant risks of both emotional and physical 'contagion' amongst individuals. Any rise in anxiety may lead to sudden changes in behavior, which can quickly lead to shortages and can enhance the need for treatment at home.
\end{abstract}

Key words: COVID-19, Psychology, Attitude, Lockdown, Anxiety, Quarantine.

\section{INTRODUCTION}

Coronavirus outbreak, or widely referred to as COVID-19, is in headline every second after it developed (or originated) in Wuhan, China, ${ }^{1}$ and is declared a pandemic by the WHO. ${ }^{2}$ Due to the exponential pattern of prevalence as well as lack of preventive vaccine, there's been a strong degree of panic in the local public. ${ }^{3}$ Of note, the prevalence of anxiety among non-medical health workers was higher even after adjustment for possible confounders. A recent research on COVID-19 reported that frontline nurses have slightly lower ratings for vicarious trauma than nonfrontline nurses and the general public (Internal Medicine Annals, 2020). ${ }^{4}$ The lack of formal psychological support, first-hand medical awareness, inadequate training on personal protective equipment and measures for infection control can be considered as factors for this. However a study reported that overall means Depression, Anxiety and stress scale
(DASS), ${ }^{5,6}$ among health care workers were lower than those in the published literature from previous disease outbreaks, such as the severe acute respiratory syndrome (SARS). ${ }^{7}$ This could be attributed to increased mental preparedness and stringent infection control measures after Singapore's SARS experience. The COVID-19 pandemic has a severe impact on the lives of individuals as a whole. Everyone in the world is directly or indirectly confronted with the serious consequences of this disease. Many countries have announced unparalleled lockdowns and emergency situations. ${ }^{8}$ Colleges, schools, pub market, shopping malls, etc. are closed by the Government. In agreement to that, the GoI (Govt. of India) has given guidance on social isolation and has effectively connected to the whole community via a number of networks. However, this epidemic due to its intense isolation and lock-down procedures causes a variety of other problems, including social
Submission Date: 16-05-2020; Revision Date: 02-07-2020; Accepted Date: 07-09-2020

DOI: 10.5530/ijper.54.3s.138 Correspondence: Dr. Shakti Ketan Prusty School of Pharmaceutical Sciences, Siksha 'O' Anusandhan (Deemed to be University), Bhubaneswar 751030, Odisha, INDIA.

Phone: +919853491143 E-mail: shaktiketanprusty@ soa.ac.in

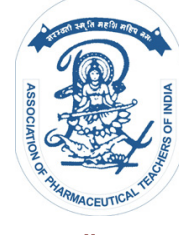

www.ijper.org 
anxieties, crisis conditions related to instability, economic recessions and severe emotional stress. Additionally, as the pandemic continues, effective clinical and policy approaches are expected to help health staff. ${ }^{9}$ Educational interventions should aim to ensure that nonmedical health workers understand and use infectious control measures. Psychological support could include counselling services and the development of support systems among peers. In this contrary, it demands a compromise between adherence to government protocols as well as self motivation to reduce the up growing stress. And hence, the inspiration given with care naturally encourages the morale of medical staff to intervene effectively with the limited resources at their disposal in order to better manage this novel pandemic. ${ }^{10}$

\section{Contributions}

- Here, we discussed about how workers migrated from urban cities to rural parts of the country gets established in different quarantine centers across the country, also discussed on taking different measures to prevent community spread of this catastrophic pandemic.

- We also analyzed the impacts and explosion that COVID-19 had in our country in the last 10 days, analyzed the infection rate, death rate, recovery rate, fatality rate, etc.

- We highlighted the psychological tool that pandemics have taken over centuries and what psychological impacts these pandemic creates on humans.

- Discussed in detail the existential questions related to COVID-19 and the impact on human psychology.

- We discussed on the different stress factors that occur amid quarantine and post quarantine and how to deal with them.

- We also analyzed the different challenges that different sectors in India are facing due to COVID19 lockdown resulting in an economic downfall and a fall in GDP rate.

- Finally, we stated precautions and preventions that citizens can take to save them and their society from getting infected from this ongoing pandemic.

\section{How migrated people can be established in quarantine centers?}

Most people who are infected with COVID-19 experience mild to moderate respiratory disease and recover without any special treatment being required. Migrant workers from rural and pre-urban parts of India who migrate to urban cities consist of a sizable amount of urban population across the country. During an outbreak, social distancing measures taken by the Government and such population tend to migrate back to their native homes. In such situations, the resultant community of migrant workers at state frontiers may render them susceptible to infection with COVID-19. ${ }^{11}$ So, as advised by the Ministry of Home Affairs (MHA), the migrant workers will remain within the city at their regular workplace or local residence. Neither their landlord nor their employer would evict them. ${ }^{12}$

Following actions could be taken at the quarantine centers to establish such migrant workers who have migrated from urban cities.

- The migrant worker's names, local residential and permanent address and mobile number shall be registered.

- The District Health administration will deploy a team that would include the District Surveillance Officer, his representative and public health personnel.

- This team shall interview persons found to be suffering from cough or fever for other symptoms related to 2019-nCoV. Furthermore, they will be asked about their history of contact with a suspect or a confirmed case on 2019-nCoV. All such people qualifying for these criteria shall be referred for 14 day solitary confinement and further testing to designated $2019 \mathrm{n}-\mathrm{CoV}$ treatment hospitals.

- A database of all migrant staff allocated to a specific quarantine facility shall be preserved.

- Adequate personnel will be mobilized to attend to the quarantine center's service, preparation, management and financial aspects.

- All such persons shall be encouraged to stay in contact with members of their family by phone to avoid anxiety and stress.

- Access control shall be enforced at these quarantine centers.

- All persons quarantined will undergo regular medical test for appearance of 2019-nCoV symptoms.

- The migrant worker will be provided a triple layered mask and sensitized on how to use and dispose of the mask, how to wash hands frequently and follow respiratory etiquettes (sneezing/coughing into tissue/flexed elbow) and also be instructed how to maintain at least 1 meter distance from each other.

- Those during the tenure of their stay are found to be symptomatic for $2019-\mathrm{nCoV}$ shall be referred to COVID-19 hospitals for testing. They will be managed as per the guidelines on management of 2019-nCoV cases and discharged as per discharge policy. 
The government of India (GoI) estimates that close to 12 lakh migrant workers have breached the lockdown and breached the roads.

\section{How to prevent community spread?}

The following instructions help prevent the spread of 2019-nCoV, as well as other outbreaks:

- Avoid personal interaction will ill individuals.

- Avoid touching your face i.e. eyes, mouth and nose.

- When you're sick, stay home.

- While sneezing or coughing, use a tissue or flexed elbow to cover it.

- Clean and disinfect frequently touched surfaces and objects every day. High touch surfaces include tabletops, counters, doorknobs, bathroom fixtures, phones, toilets and bedside tables.

- Wash your hands frequently for 20-30 sec with soap and water.

2019-nCoV spreads mainly from person-to-person. ${ }^{13}$ This could happen between people who are in close contact with each other. When an infected person sneezes or coughs, tiny droplets get formed and these droplets may land in the face of people who are nearby. This outbreak also spread from contact with infected objects or surfaces. The possibility of vast amounts of chronically ill people being unwilling to access lifesaving medical treatment is crucial to that. Hence, the best solution to stop and prevent the community spread of 2019-nCoV is to use the method of Social Distancing. It refers to actions taken to slow down the infection of a contagious disease or outbreak. It means all kinds of social gatherings in the infected zones get prohibited and people work from home most often.

Furthermore, we should use this time of social distancing as a chance to return to what we wanted to do. ${ }^{14}$ People can take steps to prevent the spread of $2019-\mathrm{nCoV}$ and help protect their community. Simple steps such as hand-washing frequently and social distancing can be very important in decreasing 2019-nCoV's impact. ${ }^{15}$

\begin{tabular}{|c|c|c|c|c|}
\hline \multicolumn{1}{|c|}{ Table 1: Data: From $6^{\text {th }}$ of May 2020 to 15 } \\
(World meters as of $\mathbf{1 5}^{\text {th }}$ May 2020). \\
\hline & \multicolumn{2}{|c|}{ Dt. 06.05.2020 } & \multicolumn{2}{|c|}{ Dt. 15.05.2020 } \\
\hline & $\begin{array}{c}\text { Total } \\
\text { Confirmed } \\
\text { Cases }\end{array}$ & $\begin{array}{c}\text { Total } \\
\text { Deceased }\end{array}$ & $\begin{array}{c}\text { Total } \\
\text { Confirmed } \\
\text { Cases }\end{array}$ & $\begin{array}{c}\text { Total } \\
\text { Deceased }\end{array}$ \\
\hline World & 826,727 & 54,598 & $4,566,476$ & 304,768 \\
\hline India & 25,117 & 904 & 83,072 & 2662 \\
\hline Odisha & 102 & 1 & 611 & 3 \\
\hline
\end{tabular}

\section{How explosive COVID-19 outbreak was in the last 10 days?}

The impact of COVID-19 in the last 10 days in the world, in India and in the state of Odisha as depicted in Table 1. It can be seen that the rates rapidly increased in India in the last 10 days causing a total of 2662 deaths in only 10 days' time period. This concerns the Government authorities of India and the ability to control the transmission of this infection. Controlling this infection has become a major issue in the state of Odisha also. Till $6^{\text {th }}$ May, Odisha witnessed and reported only 102 confirmed cases of COVID-19 but in the last 10 days the number went rapidly to double the total number of confirmed cases raising the curve up to 611 cases. In 10 days, Odisha reported a total of 509 confirmed cases. Hence it can be concluded that COVID-19 was too explosive in the last 10 days particularly in India since the total number of cases got increased at a faster pace as compared to the previous days, weeks and months. The chart below as in Table 2. compares the number of cases, number of deaths, total recoveries and total number of active cases in India vs the most affected country of World on the $102^{\text {th }}$ day after the first case.

\section{The Psychological Toll of Pandemics}

Pandemics are far from merely medicinal phenomena. They seriously damage professional and personal lives and influence multilevel individuals and communities. Physical distancing and isolation are crucial techniques encouraged for restricting an outbreak of this natureboth of them can have major impact on our relationships and our life. ${ }^{16}$ As with any other rapidly spreading virus, COVID-19 comes with an increasingly growing barrage

\begin{tabular}{|c|c|c|c|c|}
\hline \multicolumn{5}{|c|}{$\begin{array}{c}\text { Table 2: India vs the World Data comparisons } \\
\text { (Worldometers as of 15 }\end{array}$} \\
\hline Countries & $\begin{array}{c}\text { Number } \\
\text { of } \\
\text { Cases }\end{array}$ & $\begin{array}{c}\text { Number } \\
\text { of Deaths }\end{array}$ & $\begin{array}{c}\text { Total } \\
\text { Recoveries }\end{array}$ & $\begin{array}{c}\text { Total } \\
\text { Active } \\
\text { Cases }\end{array}$ \\
\hline USA & 1460902 & 87025 & 318036 & 1055841 \\
\hline Spain & 274395 & 27459 & 188967 & 57941 \\
\hline Italy & 223096 & 33186 & 109039 & 81266 \\
\hline France & 178870 & 27425 & 596405 & 91840 \\
\hline Germany & 175123 & 7933 & 151700 & 15490 \\
\hline Brazil & 179457 & 12531 & 72597 & 94329 \\
\hline Iran & 112725 & 6783 & 89428 & 16514 \\
\hline China & 82933 & 4633 & 78209 & 91 \\
\hline INDIA & $\mathbf{8 3 0 7 2}$ & $\mathbf{2 6 6 3}$ & $\mathbf{2 8 7 9 2}$ & $\mathbf{5 1 6 1 8}$ \\
\hline
\end{tabular}


of misinformation constantly being thrown at us through social media, fueling mass hysteria and stress. ${ }^{17}$ The 'fear of transmission' often engenders stigma, marginalization and xenophobia, bringing in the 'fear of fellow human beings. ${ }^{18}$ Some countries such as Italy's health machinery is creaking. Staff in the health care industry are burned out (and at high risk of infection) and medical services are reduced. Despite well-formed protocols, hospitals are over filled with testing and treatment requests while people are fiercely competing for basic healthcare amenities. There is a surge in ineffective therapies promising cure and prevention, leading to negative health consequences. Anxiety over wellbeing, panic attacks, sleep disturbances,

loneliness and depression are the other recognized pandemic mental health failures. All of these influence for many the whole issue of 'basis of life'. ${ }^{19}$ But, sadly, the emphasis of measuring the effects of COVID-19 pandemic is skewed almost entirely towards 'deaths,' although, shockingly, mental well-being, one of the major important public health measures, is being overlooked. ${ }^{20}$ Therefore, it is important to keep in mind these myriad ways in which COVID-19 pandemic might influence the mental health of people:

1. The fear of reliving a pandemic if you have encountered another pandemic/infectious disease like SARS, Ebola, or Nipah, in your lifetime.

2. The fear of livelihood loss because of isolation or travel limitation of market and social behavior (applies to sectors like fitness, travel, tourism, or food small scale industries).

3. A persistent sense of self insecurity and love for one another.

4. Societal/physical distancing distress resulting in loss of interaction with friends or family who might be living far away. For others it's the other way round: being huddled with a broad family for the first time resulting in hybrid emotions.

5. The phobia of leaving home.

6. Stigma to people with symptoms such as sneezing, cough or cold, which may simply be a flu.

7. The quintessential need to stock food essentials, or medical supplies such as pain relievers, antibiotics, face masks, anti-allergic medicines and sanitizers.

8. Psychological tension over the increasing hysteria that is compounding on a daily basis, several times because of reinforced messages in all media outlets.

9. At the frontline of COVID-19 monitoring or reporting of healthcare personnel, paramedics, virologists, volunteers or people from media: burnout, exhaustion, anger or fear and guilt of transmitting infection.
One of the important lessons learned from the MERS and SERS epidemic was the requirement for public health experts to sensitize early on the psychological effects of a pandemic and to respond to the psychological needs of those quarantined. ${ }^{18}$ The mental health and drug abuse department of the WHO has stressed the importance of mental health response to the increasing situation of COVID-19. During the initial COVID-19 outbreak in China, the researchers of China have investigated the impact of online therapy sessions on healthcare workers as well as those in isolation. Although the initial response was resentment and anger at the government, most reported better emotional satisfaction and better work environment with basic mental support even during the worsening situation in China.

A mental health school in Hunan's Second Xiangya hospital, China followed a protocol to ensure the quality of life of those in solitary confinement. The measures were easy-regular digital contact with their closed ones, community therapy, relaxation and leisure, caring for individual nutritional needs continuation of job-related tasks and updates on the state of the outbreak. Weekly psychological sessions and regular hygienic steps for a safe living were ensured. These helped to preserve the dignity of those who are self-quarantined and to respect restrictive protocols. In the absence of such treatment, we frequently see people defying isolation or absconding because of the fear of being 'stranded,' which presents a greater menace to the health of the public. ${ }^{19}$ Distancing socially (or physically) and the possibility of losing livelihoods to a systematic 'macro-stress' puts a burden on communities that are more vulnerable. Many start-ups and small-scale businesses go bankrupt and policies of the government to support them seem farfetched. In line with the steps taken during the SARS outbreak in China, support grants and insurance for these arrangements should be prioritized for these establishments. In order to protect and cultivate the most vulnerable parts of society, legal guidelines for emergency and natural calamities must be applied for pandemic situations too. ${ }^{20}$ Population of long-term isolation requiring social or financial assistance or those with compromised or deceased family members and people with lower socio-economic backgrounds with elevated risk of misinforming, require special care. ${ }^{21}$ They must also be made aware that there is assistance available.

While numerous COVID-19 aid distributors are involved, they are involved; they appear to pollute information against the infection with precautionary messages. There's rarely a 'sound' that fits those in distress and in panic. ${ }^{22}$ Major institutes such as Neurosciences 
(NIMHANS), National Institute of Mental Health and AIIMS partner with community healthcare teams to provide ongoing support for mental health services at different levels. ${ }^{23}$

\section{Existential questions}

An ongoing qualitative analysis at Christian Medical College's Department of Psychiatry and Community Health in Vellore reveals that 'existential' life and death problems derive mainly from 'fear of ambiguity' and are exacerbated by multiple sources of misinformation. There is a need for an active involvement, mainly by academics, healthcare practitioners and the media, to disseminate information at the grass root scale and to avoid 'scientific skepticism' which would have more detrimental consequences.

Debunking myths is a mutual obligation in this digital age and authenticating the truth is a must. Even one senseless message can cause snowball panic. Health care staffs are at the highest risk and require peer support services, appropriate shifts, work breaks and leave structure organization, as well as catharsis scope.

People often witness emotional distancing from family members for the culpability of infected transmission. NIMHANS experience shows that something as basic as a phone call with family members that answers their unmet needs is making a significant difference. An unknown illness has an effect far beyond its symptoms, or mortality. It is a part of our existence, which threatens our very way of life.

\section{Covid-19 Impacts on human psychology Due to these factors}

\section{Addictions}

In these recent days the alcohol shops are closed due to COVID- 19 for which the people who are addicted to the alcohols are not able to get those things. So this has created a huge impact on human psychology.

\section{ADHD}

The COVID-19 has had a significant impact on ADHD (Attention Deficit Hyperactivity Disorder) patients. The practice of social distancing in ADHD patients can lead to boredom, loneliness, isolation, anxiety, depression and many other mental health conditions.

\section{Ageing}

The impact of COVID-19 has also affected the older age people. The elders more often panic and overthink due to which they had to deal with many mental health problems as well as physical problems.

\section{Anxiety}

Currently, the anxiety is killing many minds. The more we are checking the updated news related to COVID-19, the more our anxiety is increasing and thus it is creating an unnecessary panic in everyone's mind.

\section{Children}

The COVID-19 has affected the children because the high level of stress and isolation can affect the brain development and can cause depression and anxiety.

\section{Depression}

Depression is the main impact of COVID-19 on humans. Lockdown of shops, offices, schools, colleges, industries, etc. is leading to depression and mental health retardation in humans.

\section{Emotional Health}

You may experience guilt that you are unable to help people in need or care for others. This might lead to feelings of frustration, helplessness or depression.

\section{Ethics}

You have to be ethical in this period of uncertainty. Without a second thought, always help those who are less fortunate even if it demands a bit of sacrifice from your side. Don't forget your ethics during this doomed period.

\section{Intelligence}

The spread or transmission of $2019-\mathrm{nCoV}$ is viewed as one of the biggest intelligence failures at the global level. We failed to timely and accurately detect the precise signal of COVID-19. This is a failure of human intelligence.

\section{Parenting}

The parents during the COVID-19 are getting enough time to spend with their children. They should help their children by decreasing their fear of news they hear and also by recognizing their feelings on different issues.

\section{Race}

Most black and Hispanic Americans do not have any financial reserves to cover expenses in case of any emergency. They are experiencing job and wage loss due COVID-19 outbreak.

\section{Sexuality}

Sexuality is about your sexual feelings, thoughts, attractions and behaviors towards other people.

\section{Stress}

have an equal probability of having COVID-19, globally, with gender-disaggregated results, men's deaths outweigh women. The cause are not yet known but are believed to be linked to sex differences in the immune system's reaction, i.e. biological rather than social influences.

The news of COVID-19 is pouring in and the information are overwhelming and scary. This is causing 
stress in human beings and is affecting both physically and mentally.

\section{Therapy}

Since any antidote vaccine is yet to be discovered, therapy for fighting COVID-19 took a backseat. Medical staffs are highly relying on different types of medicines and tablets like HCQ (200mg), Lopinavir and Ritonavir, Tocilizumab, Tamiflu capsules, Paracetamol and Azithromycin for the therapy.

\section{Trauma}

Despite human tolerance, notably in global catastrophic events such as impending COVID-19 crisis, human vulnerability, both emotionally and physically, can't be taken for granted. The psychological nature of trauma affects human behavior; instead, any interaction the victim has with themselves and with the people around them.

\section{Workplace Issues}

In India, many states have been subjected to a circumstance of complete lockdown, which has forced workers to question whether they can hold their citizens safe, avoid the dissemination of the epidemic and manage to function efficiently throughout this ongoing crisis.

\section{House conflict}

During this COVID-19 crisis, as anxiety and fear is increasing, conflict is occurring in families with risk factors like drug and alcohol abuse, domestic violence and mental health diagnoses. All are at a risk of house conflict.

\section{Human being social animal}

Fear to the social contact, emotional break up The people in this pandemic lockdown are practicing social distancing to avoid contamination of the virus. Due to this they are increasing their social contact with their family members. If one member of the family is coming from other town or state, then they are distancing themselves from them, although to safeguard themselves.

\section{Detached with emotional touch, because $80 \%$ is asymptotic}

Asymptotic means people are not aware that they have mild symptoms and are affected which leads to emotional detachment or barrier among family members due to this social distancing and asymptotic people being in solitary confinement.

20. Suicide rate will be increased (Arunachal Pradesh Female, Germany financial minister, Dubai industrialist)

Due to the complete lockdown in India, in many states, suicide rates are increasing due to panic, anxiety attacks; fear of losing jobs and businesses, starvation and also due to the influx of migrant workers from urban cities to rural villages.

21. GDP will be zero (Moody's forecast at 0.0, 20212022, before it forecast 2.6.)

On a positive note, prediction is India's GDP growth rate will bounce back to 6.6 per cent in FY 2021-2022. Government of India steps to boost the economy would help to reduce the extent and length of India's slowdown in production.

\section{Stress during Quarantine}

\section{i. Quarantine Duration}

Many studies have shown that longer quarantine durations are directly correlated with poor mental wellbeing, avoidance habits, post-traumatic stress symptoms and frustration. While the length of the quarantine was not always apparent, one study found that those who are in solitary confinement for 10 days witnessed signs of post-traumatic stress substantially higher than those quarantined for fewer than 10 days. ${ }^{24}$

\section{ii. Fear of Infection}

Participants in 8 studies expressed fears about their health or worries (or fears) of infecting other people and were more likely than those not in solitary confinement to risk infecting family members. Particularly, they became more worried if they encountered any physical symptoms possibly related to the infection and they were afraid that the symptoms could indicate that the infection appeared to be linked to psychological results even after several months. ${ }^{25}$

\section{iii. Boredom and Frustration}

Confinement, lack of daily routine and decreased social and physical interaction with others have also been shown to trigger boredom, dissatisfaction and a sense of alienation from the rest of the world. This dissatisfaction was compounded by not being able to engage in the normal everyday tasks, such as taking part in social networking events via phone call and Internet, or shopping for basic needs.

\section{iv. Lack of Supplies}

Having insufficient basic quintessential supplies amid quarantine (e.g. water, clothes, food, or accommodation) was a source of irritation and continued to be related with anxiety and rage 4-6 months after release. It also seemed to be a concern with some participants not being able to get routine medical treatment and medications. For reports we found inadequate resources from public health authorities. Participants reported getting their thermometers and masks late or not all; water, food and other products were distributed only intermittently; and it took a long time for food supplies to arrive. 
Even though those quarantined during the Toronto SARS outbreak thanked public health authorities for distributing medical supply kits at the beginning of the quarantine phase, they did not obtain foodstuffs or other daily supplies required for everyday life.

\section{v. Lack of Information}

Many participants reported inadequate information from public health authorities as a stressor, citing insufficient clear guidance on action to be taken and uncertainly over the quarantine intent. After the SARS outbreak in Toronto, participants believed that uncertainty resulted from the variations in the design, method and content of different public health campaigns due to inadequate communication between the concerned multiple jurisdictions and government levels. In particular, lack of information about the various levels of danger led participants to expect the worse. Participants have also mentioned a perceived lack of accountability on the seriousness of the pandemic from health and government officials. May be due to the lack of explicit instructions or justification, perceived difficulty complying with solitary confinement protocols in one study was a major predictor of post-traumatic stress symptoms. ${ }^{25}$

\section{Stress after Quarantine}

\section{i. Finance}

During quarantine, financial loss may be a concern, with people unable to work and needing to disrupt their professional activities without prior planning; the effect seems long lasting. ${ }^{26}$ The financial loss resulting from quarantine generated severe socio-economic distress in the reviewed and was found to be a risk factor for symptoms of psychiatric disorders and both frustration and anxiety several months after solitary confinement. ${ }^{27}$ One study shows that respondents who were in solitary confinement due to equine influenza, whose main source of income was from horse-related industry, were more than twice as likely to experience high distress relative to those whose income wasn't from industry. This function is likely to be related to economic effects, but could also be associated to instability of social networks and loss of leisure.

A survey of people quarantined due to possible Ebola interaction found that while participants received financial assistance, some thought the amount was inadequate and it arrived too late; others thought misled because the assistance they received didn't cover their ongoing health expenses. Many were dependent on their families during quarantine to provide for them financially which was often difficult to accept and can cause issues. None of those quarantined in Toronto during SARS showed any financial distress in one study as they were paid by government or employers, but when that paycheck took too much of time to arrive it caused the less financially well-off to suffer. ${ }^{28}$ Participants with a gross annual household income of under CAN $\$ 40,000$ reported substantially higher levels of post-traumatic stress and depressive symptoms possibly linked to financial loss. Such symptoms are possibly because the temporary loss of income was more likely to affect those with low incomes than those with higher incomes. People who are in solitary confinement (or quarantined) who have lower household incomes and require additional support rates, along with others who lose earnings while in solitary confinement (or quarantine) (i.e., self-employed people who are unable to function or salaried workers who are unable to grant paid sick leave. Where appropriate, financial reimbursements should be made and programs established to provide financial support during the quarantine phase. Where applicable, employers may also want to consider constructive solutions that encourage workers to work from home if they so desire, both to prevent financial losses and to keep off boredom, while keeping in mind that workers in these circumstances may not be most productive and may gain more from their colleague's remote social support.

\section{ii. Stigma}

Stigma from other people has been a common theme in the literature, frequently continuing after quarantine for some time, often after the epidemic is contained. Comparing health care workers those who are quarantined with those who were not quarantined, quarantined people were slightly more likely to experience stigma and disapproval from residents in their local communities, indicating that particular stigma affect individuals who have been in solitary confinement (or quarantine).

Participants in many studies mentioned being viewed differently by others; ignore them, withhold social invites, view them from fear and mistrust and make critical comments. Many healthcare workers engaged in Senegal's Ebola outbreak claimed that quarantine had led their families to find their jobs too dangerous, causing stress within family. ${ }^{14}$ In the same analysis, 3 participants reported being unable to restart their employment after surveillance had ended due to fear of contagion expressed by their employees.

Many quarantined during Liberia's Ebola epidemic stated that stigma could contribute to the disenfranchisement of minority groups within the community as families 
under quarantine belong to various ethnic groups, religions, or races and were regarded as unsafe as they were different. Maybe because of this fear, being quarantined led participants in this study to keep it easy to handle, non-Ebola diseases are a secret and they stopped seeking help.

Basic education about the infection and the reason for solitary confinement and public health information provided to the public can be effective in reducing stigma, while more detailed data targeted at schools and workplaces could also be beneficial. This may also be that media coverage leads to stigmatizing attitudes in the general population; media is a strong influence on public perceptions and it has been shown that sensational news and fear mongering lead to stigmatizing perceptions in the past (e.g. during the period of SARS outbreak). This problem illustrates the need for public health officials to deliver timely, concise messaging efficiently distributed to the entire affected population in order to facilitate accurate knowledge of the situation. ${ }^{22}$

\section{Challenges faced by different sectors}

\section{FMCG sector}

If the supply chain doesn't return to normal quickly, the packaged food industry could run out within a week to 10 days. According to data by Nielsen, ${ }^{23}$ the FMCG sector could experience a sharp decline in their sales. Consumers would react in a bearish way while spending on their wants such as watching movies in theatres, going to hotels, etc. They may also spend less on tobacco and alcohol products.

\section{Construction and Real Estate Industry}

There are multiple challenges that this industry could face once the lockdown ends. A few issues to name are availability of workforce, monitoring worker's health, supply of raw materials and ensuring free flow of funds to execute work without any hassles. Because many workers will go to their native places after the lockdown. Many projects will get delayed and unit costs will also get delayed amidst all the logistic and practical issues. There could be a reduction in the rate for home loan interest for buying in the next 6 months or so.

\section{Restaurant Industry}

The restaurant industry, along with the travel and aviation industry, has been the biggest hit. Recovery of this industry is very important to the country's growth since this sector contributes $2 \%$ of India's GDP. This industry is now facing an existential crisis. Some of the sew issues include feeding millions of people, rents to pay and with zero revenue coming in nowadays amidst the lockdown it's truly a crisis of epic proportions.

\section{Aviation Industry}

They could face difficulty in restarting logistics, in restarting the entire global network due to initial low load factors, in restarting the entire disruptions that the COVID-19 has caused.

\section{Supply Distributions}

It results in widespread disruption of supplies like vegetables, medicines and milk which is a major issue among others. This is because states have sealed borders, cutting off freight corridors and delivery trucks are also being blocked by cops. Logistical challenges are being faced by grocery vendors. Daily wage workers would struggle to feed families. E-commerce companies could face difficult challenges to get passes for delivery and logistics.

These are the major issues and challenges that various industries and sectors could and would most probably face after the lockdown period gets over.

\section{Precautions}

- SICP (Standard infection control precautions) - It diminish the risk of transmission of toxic agents from both recognized and unrecognized origin. It should be used by all staff, in all care frameworks for all patients.

- Transmission Based Precautions (TBP) definitionThis is only tested when SICP alone is inadequate to prevent cross transmission of a toxic agent. TBP are categorized by the line of transmission of the infectious agent.

- Routes of transmission

1. Contact Precautions- This is the most common route of transmission of infection and is used to prevent and monitor transmission of infection via direct and indirect treatment tools.

2. Droplet Precautions-It block short distances via droplets from respiratory portion of one individual directly onto a mucosal side or another individual concerted. The maximum distance for cross transmission from droplets has not be determined and length is approx. 1 meter i.e. 3 feet.

3. Airborne Precautions- Aerosols penetrate to the alveolar portion of the respiratory system. It is approached closely via aerosols from one single respiratory tract directly onto a mucosal surface.

- Patient assessment for infection risk- Patients are check for infection risk on landing at the care area and if possible preceding peoples are accepting patients from other area.

- Hand hygiene- It diminish the transmission of infection in health and has a demanding element 
of SICP. As all staff, patients, doctors and visitors sanitize their hand with Alcohol Based Hand $\operatorname{rub}(\mathrm{ABHR})$, when arriving and leaving the COVID19 infected areas.

- Use of Personal Protective Equipment (PPE)-It provide capable protection against the risks associated with the measure or task being undertaken. All staff should be skilled in the proper use of all PPE that they may be required to wear perfectly.

- Packing and transporting of patient-care equipment, linen, laundry and waste from isolation fields, as well as preventing needle-stick or spot injuries.

Standard Precautions should be taken care for Infection Control and Prevention:

- Patient assessment for infection risk

- Hand hygiene

- Respiratory and cough hygiene(Cough Etiquette)

- Personal protective equipment (PPE)

- Safe management of equipment associated with the doctors

- Safe management of environment i.e. Cleaning and Disinfection andWaste Disposal

- Safe management of blood and body fluids

- Safe management of linen

- Needle stick and Sharps Injury Preventions

- Safe Injection Practices

Additional precautions should be taken care, which includes:

1. Implement Telehealth and Nurse-Directed Triage Protocols

2. Screen and triage everyone entering a healthcare facility for signs and symptoms of COVID-19

3. Re-evaluate admitted patients for signs and symptoms of COVID-19

4 Implement universal source control measures

5. Encourage physical distancing

6. Implement universal use of personal protective equipment

7. Consider Performing Targeted SARS-CoV-2 testing of patients without signs or symptoms of COVID-19

8. Consider if elective procedures, surgeries and nonurgent outpatient visits should be postponed in certain circumstances.

9. Optimize the use of engineering controls and indoor air quality

\section{Transmission Based Precaution}

1. Establish Reporting within and between healthcare facilities and to public health authorities
2. For patients with COVID-19 or other respiratory infections, evaluate need for hospitalization.

3. Personal Protective Equipment (PPE) should be primary importance.

4. Healthcare personnel (HCP) should perform hand hygiene before and after all patient contacted.

5. Personal Protective Equipment Training must be conducted by the expert members.

6. Respirator or Facemask (Put on an N95 respirator or facemask before entry into the patient room )

7. Eye Protection(disposable face shield or goggles should be covered the front and sides of the face)

8. Put on clean, non-sterile gloves upon entry into the patient room or care area

9. Put on a clean isolation gown upon entry into the patient room or area.

10.Aerosol Generating Procedures (AGPs) procedures performed on patients with suspected or confirmed SARS-CoV-2 infection.

11.Collection of diagnostic respiratory specimens

12.Manage visitor access and movement within the facility

13.Mostly environmental infection control must be taken care

\section{Prevention}

- Lockdown - nationwide lockdown apply for some days, limiting the travel of all of India's population as a prevention step against the COVID-19 pandemic in India in 2020.

- Hand washing- Wash hands regularly and correctly, use clean running water and mild water. If soap and water are not possible, clean hands using an alcohol-based hand sanitizer.

- Immunizations- For preventing disease, vaccines is the crucial as it is benefit both the people who get that and also for vaccination peoples around them. Vaccines diminish the number of death rate and aliment from infections.

- Cover face during cough or sneeze and washing hand after coughing or sneezing.

- Using N95 mask while traveling or working in public places to avoid droplet transportation.

- Avoid stunning eyes, nose and mouth with undesirable hands and also close contact with the people whose who are sick rather should stay at home to be safe.

- Clean and sanitize frequently touched surfaces and objects.

- Be socially responsible-Large gathering/crowded are not allowed because it may cause to COVID-19. 
- Social distancing: To maintain distance between number people at the time of working period. The Government were added various rules to avoid infection during Covid-19 virus through social distancing and preventive actions. But most of the literate persons are more aware to avoid infections by following the rules and guidelines of health organization. Those people are not serious about it which will cause a main medium to spread this infection to all areas. That's why need more awareness program as well as proper analysis of mental or physical health case of people through coronavirus survey.

\section{CONCLUSION}

During this COVID-19 pandemic most educated people were aware of this situation and healthcare practitioners are aware of this infection and potential preventive measures, the importance of social distancing between policy initiatives and society had been taken to restrict the transmission of the infection. There are, however, increased public fears and apprehensions about the acquisition of the COVID-19 infection. Individuals have significantly higher needs to cope with their mental health issues. The awareness campaign needs to be stepped up and people's mental health issues tackled during this pandemic. To date, there is no report that measured people's mental health outlook during the pandemic. To plan appropriate therapeutic approaches for them, it is crucial to research the impacts of mental health in various populations (general public, COVID19 incidents and healthcare workers).

\section{ACKNOWLEDGEMENT}

The authors are thankful to the management of Siksha O Anusandhan University, Bhubaneswar, Odisha for funding this work and Regional Medical Research Centre (RMRC), Bhubaneswar for providing library facility.

\section{CONFLICT OF INTEREST}

The authors declare no conflict of interest.

\section{REFERENCES}

1. Wang DB, Hu C, Hu F, Zhu X, Liu J, Zhang B, et al. Clinical characteristics of 138 hospitalized patients with 2019 novel coronavirus-infected pneumonia in Wuhan, China. JAMA. 2020;323(11):1061-9. [cited 2020 Mar 23]Sohrabi C, Zaid A, O'Neill N, Mehdi K, Ahmed K, Al-Jabir A, et al. World Health Organization declares global emergency: A review of the 2019 novel coronavirus (COVID-19). International Journal of Surgery. 2020.

2. Ti LK, Lin SA, Theng WF, Bryan SWN. What we do when a COVID-19 patient needs an operation: operating room preparation and guidance. Canadian Journal of Anesthesia/Journal Canadien D'anesthésie. 2020;1-3.
3. DeAzambuja E, Lieveke A, Marianne PC, Zielinski C, Piccart-Gebhart M, Matthias P. The landscape of medical oncology in Europe by 2020. Annals of Oncology. 2014;25(2):525-8.

4. Gloster AT, Howard MR, Diane N, Jens K, Ashley S, Mark K, et al. Psychometric properties of the Depression Anxiety and Stress Scale-21 in older primary care patients. Journal of Affective Disorders. 2008;110(3):248-59.

5. Parkitny L, McAuley J. The depression anxiety stress scale (DASS). J Physiother. 2010;():204.

6. Ksiazek TG, Dean E, Cynthia S, Goldsmith SR, Zaki TP, Shannon E, et al. A novel coronavirus associated with severe acute respiratory syndrome. New England Journal of Medicine. 2003;348(20):1953-66.

7. World Health Organization. Modes of transmission of virus causing COVID-19: implications for IPC precaution recommendations: Scientific Brief. 2020. WHO/2019-nCoV/Sci_Brief/Transmission_modes/2020.1. World Health Organization. 2020.

8. Elfiky AA. Anti-HCV, nucleotide inhibitors, repurposing against COVID-19. Life Sciences. 2020;117477.

9. COVID, CDC and Response Team. Severe outcomes among patients with coronavirus disease 2019 (COVID-19): United States. MMWR Morb Mortal Wkly Rep. 2020;69(12):343-6.

10. Cetron M, Julius L. Public health and ethical considerations in planning for quarantine. The Yale Journal of Biology and Medicine. 2005;():329.

11. Mishra S, Archisman M, Raman K, Anjana S, Ajeet SB, Ravi K. Restricting rural-urban connect to combat infectious disease epidemic as India fights COVID-19. Journal of Family Medicine and Primary Care. 2020;9(4):1792.

12. Sajadi MM, Parham H, Augustin V, Shervin S, Miralles-Wilhelm F, Anthony A. Temperature and latitude analysis to predict potential spread and seasonality for COVID-19. Available at SSRN 3550308. 2020.

13. Kannan SP, Shaik SA, Sheeza A, Hemalatha K. COVID-19 (Novel Coronavirus 2019)-recent trends. European Review for Medical and Pharmacological Sciences. 2020;():2006-11.

14. Brooks SK, Rebecca KW, Louise ES, Lisa W, Simon W, Neil G, et al. The psychological impact of quarantine and how to reduce it: Rapid review of the evidence. The Lancet. 2020.

15. Rehman U, Shahnawaz MG, Khan NH, Kharshiing KD, Khursheed M, Gupta K, Kashyap D, Uniyal R. Depression, Anxiety and Stress Among Indians in Times of Covid-19 Lockdown. Community mental health journal. 2020; (23):17.

16. Cascella M, Rajnik M, Cuomo A, Dulebohn SC, Di Napoli R. Features, evaluation and treatment coronavirus (COVID-19). InStatpearls [internet] 2020 Mar 8. StatPearls Publishin

17. Wang C, Riyu P, Xiaoyang W, Yilin T, Linkang X, Cyrus SH, et al. Immediate psychological responses and associated factors during the initial stage of the 2019 coronavirus disease (COVID-19) epidemic among the general population in China. International Journal of Environmental Research and Public Health. 2020;():1729.

18. Casagrande M, Francesca F, Renata T, Giuseppe F. The enemy who sealed the world: Effects quarantine due to the COVID-19 on sleep quality, anxiety and psychological distress in the Italian population. Sleep Medicine. 2020.

19. Roy D, Sarvodaya T, Sujita KK, Nivedita S, Sudhir KV, Vikas K. Study of knowledge, attitude, anxiety and perceived mental healthcare need in Indian population during COVID-19 pandemic. Asian Journal of Psychiatry. 2020;102083.

20. Forte G, Francesca F, Renata T, Maria C. COVID-19 Pandemic in the Italian Population: Validation of a Post-Traumatic Stress Disorder Questionnaire and Prevalence of PTSD Symptomatology. International Journal of Environmental Research and Public Health. 2020;():4151.

21. Cao W, Ziwei F, Guoqiang $\mathrm{H}$, Mei H, Xinrong $X$, Jiaxin D, et al. The psychological impact of the COVID-19 epidemic on college students in China. Psychiatry Research. 2020;112934.

22. Ho CSH, Cornelia YC, Roger $\mathrm{CH}$. Mental health strategies to combat the psychological impact of COVID-19 beyond paranoia and panic. Ann Acad Med Singapore. 2020;(1):1-3.

23. Li Z, Jingwu G, Meiling $Y$, Jianping $F$, Mei $Q$, Riyue J, et al. Vicarious traumatization in the general public, members and non-members of medical teams aiding in COVID-19 control. Brain, Behavior and Immunity. 2020.

24. Duan L, Gang Z. Psychological interventions for people affected by the COVID-19 epidemic. The Lancet Psychiatry. 2020;7(4):300-2. 
Wang G, Yunting Z, Jin Z, Jun Z, Fan J. Mitigate the effects of home confinement on children during the COVID-19 outbreak. The Lancet. 2020;():945-7.

26. estimates of mortality following COVID-19 infection. The Lancet Infectious Diseases. 2020.
27. Forte G, Francesca F, Renata T, Maria C. The Enemy Which Sealed the World: Effects of COVID-19 Diffusion on the Psychological State of the Italian Population. Journal of Clinical Medicine. 2020;():1802.

28. Favieri F, Giuseppe F, Renata T, Maria C. The Italians in the time of Coronavirus: Psychosocial aspects of unexpected COVID-19 pandemic. Available at SSRN 3576804. 2020.

Cite this article: Singh D, Prusty SK, Sarangi SS, Sahoo S, Biswal AK. Attitude, Anxiety, Psychological Effects and Prevention during COVID-19 in India. Indian J of Pharmaceutical Education and Research. 2020;54(3s):s400-s410. 